\title{
Práticas educativas em tempos de pandemia: relato de experiência
}

\author{
Educational practices in pandemic times: \\ experience report
}

\section{Prácticas educativas en tiempos de pandemia: informe de experiencia}

Elisangela Alves dos Reis' https://orcid.org/0000-0002-59|3-826| Patrícia de Araujo Abucarma Stevanato² https://orcid.org/0000-000 I-5199-3055 Mauriza Gonçalves de Lima Menegasso ${ }^{3}$ https://orcid.org/0000-0003-3020-12IX

Resumo: O presente relato tem como objetivo destacar o percurso e práticas educativas propostas para a Educação Infantil, anos iniciais do Ensino Fundamental, Educação Especial e Educação de Jovens e Adultos - FASE I, em tempos de COVID-19, na Rede Municipal de Ensino de uma cidade do Noroeste do Paraná. A pesquisa, de caráter qualitativo, investigou quais práticas docentes e atividades metodológicas foram adotadas no recorte temporal de março a junho de 2020, a fim de possibilitar a continuidade das experiências educativas, respeitando o distanciamento social e mantendo a interação docentes e discentes. O cotejamento das informações permitiu identificar que, dentre as alternativas metodológicas apresentadas pelo Ministério da Educação e Secretaria de Estado da Educação do Paraná como opções para continuidade do processo educacional, a rede optou pela realização de atividades não presenciais com base na elaboração de cadernos de atividades impressos, vídeos instrucionais direcionados às famílias e interações assíncronas via WhatsApp, garantindo, portanto, o acesso de

'Doutora. Professora. Prefeitura Municipal de Umuarama. ORCID https://orcid.org/0000-0002-59|3-826I. elysreis@hotmail.com

${ }^{2}$ Mestre. Professora. Prefeitura Municipal de Umuarama. ORCID https://orcid.org/0000-0001-5199-3055. patriciaaburcarma@umuarama.pr.gov.br

${ }^{3}$ Especialista. Secretária Municipal. Prefeitura Municipal de Umuarama. ORCID https://orcid.org/0000-00033020-I2IX. maurizaglima@gmail.com

Olhar de professor, Ponta Grossa, v. 24, p. I-8, e-16178.020, 2021.

Disponível em <https://revistas2.uepg.br/index.php/olhardeprofessor> 
um número maior de estudantes às práticas educativas e mantendo a proximidade das relações de aprendizagem, do que se elas fossem mediadas apenas por plataformas online.

Palavras-chave: Educação. Atividades não presenciais. Pandemia.

Abstract: This report aims to highlight the educational path and practices proposed for Early Childhood Education, early years of Elementary Education, Special Education and Youth and Adult Education - PHASE I, in Covid-19 times, in the Municipal Education Network of a city in the Northwest of Paraná state. The qualitative research investigated which teaching practices and methodological activities were adopted in the time frame from March to June 2020 in order to enable the continuity of educational experiences, respecting social distance and maintaining interaction. The comparison of the information collected made it possible to identify that among the methodological alternatives presented by the Ministry of Education and the State Secretariat of Education of Paraná as options to continue the educational process, the network opted for carrying out non-classroom activities. These activities were based on the elaboration of printed activity books, instructional videos to families and asynchronous interactions via WhatsApp, thus providing a greater number of students with access to educational practices and keeping the proximity of relationships more successfully than if only mediated by online platforms.

Keywords: Education. Non-Presential Activities. Pandemic.

Resumen: Este informe tiene como objetivo resaltar la trayectoria educativa y las prácticas propuestas para la Educación Infantil, los primeros años Educación Primaria, Educación Especial y Educación de Jóvenes y Adultos FASE I, en tiempos de Covid-19, en la Red de Educación Municipal de una ciudad del Noroeste del Paraná. En el estudio, de carácter cualitativo, se investigaron qué prácticas docentes y actividades metodológicas se adoptaron en el marco temporal de marzo a junio de 2020 para posibilitar la continuidad de las experiencias educativas, respetando la distancia social y manteniendo la interacción. La comparación de la información permitió identificar que entre las alternativas metodológicas presentadas por el Ministerio de Educación y la Secretaría de Estado de Educación de Paraná como opciones para continuar el proceso educativo, la red optó por realizar actividades no presenciales basadas en la elaboración de libros de actividades. videos instructivos impresos para las familias e interacciones asincrónicas a través de WhatsApp. Así se aseguró que hubiera un mayor número de estudiantes con acceso a prácticas educativas que si se mediaran únicamente por plataformas en línea, y se mantuvo la proximidad de las relaciones.

Palabras clave: Educación. Actividades no presenciales. Pandemia.

\section{Introdução}

A pandemia do coronavírus (SarsCoV-2, causador da COVID-19) tem trazido novos desafios e demandas de reorganização a todas as relações sociais e instituições da sociedade em todos os países do mundo.

Diante do cenário brasileiro, o Governo Federal publicou a Lei n. 13.979, de 6 de fevereiro de 2020, que conceitua dois termos que passam a fazer parte do cotidiano de todos os cidadãos brasileiros. São eles o isolamento, que é definido no art. $2^{\circ}$, inciso I, como "separação de pessoas doentes ou contaminadas, ou de bagagens, meios de transporte, mercadorias ou encomendas postais afetadas, de outros [...]" (BRASIL, 2020) e quarentena, que é conceituada no art. $2^{\circ}$, inciso II, como "restrição de atividades ou separação de pessoas suspeitas de contaminação das pessoas que não estejam doentes [...]" (BRASIL, 2020a). A adoção dessas medidas mudou de forma extrema as rotinas diárias de organização pessoal da maior parte da população, bem como das mais diversas instituições sociais, sobretudo dos processos educacionais.

Olhar de professor, Ponta Grossa, v. 24, p. I-8, e-16178.020, 2021.

Disponível em <https://revistas2.uepg.br/index.php/olhardeprofessor> 
Elisangela Alves dos Reis, Patrícia de Araujo Abucarma Stevanato e Mauriza Gonçalves de Lima Menegasso

Instituições de ensino de todos os níveis da educação tiveram que, aceleradamente, fechar suas portas, suspender o atendimento presencial e acatar as orientações provenientes dos órgãos públicos, o que culminou no distanciamento social, a fim de diminuir a interação entre as pessoas que convivem no espaço escolar e diminuir a velocidade de transmissão do vírus. No Paraná, as escolas foram fechadas a partir do dia 20 de março de 2020, em conformidade com o Decreto n. 4.230, de 16 de março de 2020, expedido pelo Governo do Estado (PARANÁ, 2020). Os desdobramentos dessa ação se materializaram no Parecer CNE/CEB n 5/2020, de 28 de abril de 2020 (BRASIL, 2020b), do Conselho Nacional Educação (CNE) e do Câmera de Educação Básica (CEB), e na aprovação da veiculação da proposta de reorganização do Calendário Escolar e da possibilidade de cômputo de atividades não presenciais para fins de cumprimento da carga horária mínima anual, em razão da Pandemia da COVID-19.

Essa necessidade de alteração aligeirada para uma nova forma de fazer educação provocou incertezas, angústias e novos desafios aos gestores, professores, estudantes, famílias e demais atores com ela envolvidos. A docência em tal cenário complexo exige do professor uma postura de mediador de aprendizagens; logo, pressupõe uma atitude diferente da convencional. O professor deixa ○ papel de "informador", aquele que centraliza a informação, que só fazia sentido quando o acesso à informação era difícil (MORAN, 20I5).

Posto isso, pretendemos relatar a experiência de um munícipio do Noroeste do Paraná, no que tange ao percurso e às práticas educativas adotadas no cenário da pandemia de COVID-19, que compele a pensar em outros meios de dar continuidade ao processo de ensino e aprendizagem de estudantes da educação básica.

A fim de conduzir a estrutura de organização deste trabalho, elegemos o gênero textualdiscursivo denominado relato de experiência para, de acordo com Schneuwly e Dolz (2010), construir um texto em que a representação das situações vividas fosse posta em discurso. Além disso, compreendemos que "o relato de experiência permite a apreensão de conteúdos numa perspectiva que envolve tanto a interpretação quanto a produção do vivenciado" (CARVALHO, 20 I , p.59).

\section{As práticas educativas e seu lugar social de produção}

Este relato de experiência tem como objetivo apresentar as medidas adotadas pela Secretaria Municipal de Educação de uma cidade do Noroeste do Paraná, com I 10.590 habitantes, sendo 9.100 estudantes matriculados na Educação Infantil, Ensino Fundamental e EJA-Fase I (Educação de Jovens e Adultos - Fase I).

Com base no Parecer CNE/CEB n 5/2020, de 28 de abril de 2020, o qual estabelece que "materiais de orientações aos pais ou responsáveis com atividades educativas de caráter 
Práticas educativas em tempos de pandemia: relato de experiência eminentemente lúdico, recreativo, criativo e interativo," (CNE, 2020b, p. 9) podem ser enviados para as casas dos estudantes enquanto durar a pandemia, propuseram-se possibilidades e alternativas para que o processo de ensino e aprendizagem continuasse mesmo diante dos desafios que essa nova forma de organização e estruturação pedagógica pudesse requerer.

Contudo, conscientes de que vivemos uma situação de excepcionalidade, que o ensino presencial não é uma opção para este período histórico atípico, as atividades não presenciais constituem uma possibilidade de garantia da oferta e continuidade das experiências educativas para a Educação Infantil, Ensino Fundamental, Educação Especial e EJA. Nessa conjuntura, a seguinte problemática surgiu: Como garantir a todos os estudantes o acesso ao processo de aprendizagem? Visto que a mediação por tecnologias, que é um dos caminhos possíveis para diminuir a lacuna do ensino presencial, demanda certa autonomia dos estudantes ou a mediação de um indivíduo mais experiente esta poderia tornar-se mais uma responsabilidade atribuída amplamente às famílias. Porém, algumas das famílias têm relatado muitas outras preocupações nestes tempos, tais como necessidades econômicas, de saúde, inteligência emocional e experiência em outros ofícios não relacionados à educação.

$\mathrm{Na}$ análise do cenário, no referido recorte temporal, outra dificuldade verificada é que algumas famílias dos estudantes da Rede Municipal não dispunham de computadores e internet banda larga, ou sequer destreza ao utilizá-los enquanto ferramenta pedagógica, para que se adotem as salas de aula digitais, com atividades síncronas e assíncronas como, por exemplo, o Google Classroom ${ }^{\circledR}$. Ao contrário, os equipamentos tecnológicos são comumente utilizados como ferramenta de comunicação e entretenimento, e a maior parcela desse público utilizava com frequência, quando contratava pacote de dados móveis, apenas o WhatsApp.

A discussão quanto ao uso das tecnologias nos processos educacionais é antiga e fecunda. "Estamos em um mundo em que as tecnologias interferem no cotidiano, sendo relevante, assim, que a educação também envolva a democratização do acesso ao conhecimento, à produção e à interpretação das tecnologias" (BRITO, 2006, p. 20). No entanto, como democratizar o acesso ao conhecimento para um público que não tem acesso sequer às tecnologias básicas? Como pensar em utilizar a tecnologia na Educação Infantil, Anos Iniciais e EJA-FASE I sem notar a desigualdade de modo a promover o acesso equitativo para todos?

Com base no mapeamento apresentado e sob os pressupostos das problemáticas anteriores, a Rede Municipal optou por duas frentes de atuação, uma para os estudantes da Educação Infantil e outra para os estudantes do Ensino Fundamental I, Educação Especial e EJA. Para as crianças menores, atendidas no CMEI (Centro Municipal de Ensino Infantil), o acesso ao conteúdo educacional pautou-se na produção de vídeos assíncronos com orientações para as famílias quanto à necessidade de 
Elisangela Alves dos Reis, Patrícia de Araujo Abucarma Stevanato e Mauriza Gonçalves de Lima Menegasso estabelecer uma rotina para as crianças, com momentos para higiene pessoal e alimentação, privilegiando as interações e brincadeiras.

A construção de significações no estudante, a gênese do pensamento e a constituição de si mesmo como sujeito se fazem graças às interações constituídas com outros parceiros em práticas sociais concretas de um ambiente que reúne circunstâncias, artefatos, práticas sociais e significações. "Sendo ação partilhada, a interação é influenciada por características de ambos os parceiros". (OLIVEIRA, 2007, p. 135). As interações e brincadeiras, os estímulos e mediações pedagógicas, anteriormente realizadas pelo professor, são agora mediados pelos familiares, sob a prescrição do docente da Educação Infantil, a fim de dar continuidade aos processos de desenvolvimento da criança e estreitar vínculos, uma parceria entre família e unidade educacional fundamental.

Para os estudantes do $1^{\circ}$ ao $5^{\circ}$ ano e da SRM (Sala de Recursos Multifuncional), as intervenções pedagógicas de continuidade das experiências educacionais fundamentaram-se na elaboração e distribuição de cadernos de atividades impressos, bem como na produção e divulgação de vídeos assíncronos explicativos para orientar as famílias quanto ao uso desses materiais e à atuação do familiar mediador.

Os cadernos de atividades para os estudantes do $1^{\circ}$ ao $5^{\circ}$ ano foram construídos de forma colaborativa e dialogada, por meio da participação das coordenações educacionais da SME (Secretaria Municipal de Educação), gestores e professores das unidades educacionais, compostos por um compilado dos objetos de conhecimento referentes aos componentes curriculares de Arte, Ensino Religioso, Educação Física, História, Ciências, Geografia, Matemática e Língua Portuguesa, prescritos para $\circ 1^{\circ}$ semestre, com atividades para um período de 60 dias.

As atividades foram estruturadas, primeiramente, pelas respectivas Coordenações Educacionais dos componentes curriculares com base no currículo do primeiro semestre do ano corrente. Num segundo momento, foram disponibilizados para que as Coordenações Pedagógicas encaminhassem aos professores de cada turma, para que pudessem revisar o material e, posteriormente, repassar à Coordenação para que esta o enviasse à SME para a respectiva formatação e posterior diagramação. Participaram desse processo 600 professores, 22 diretores, 21 coordenações pedagógicas e 10 coordenações educacionais da SME.

Para os estudantes com necessidades educacionais especiais matriculados na Sala de Recursos Multifuncional foi elaborado um caderno suplementar composto de atividades práticas e ludopedagógicas de estimulação da coordenação motora, discriminação visual e orientação espacial, com exercícios de recorte, colagem e treino para a escrita, que deveriam ser realizados em contraturno escolar. 
Práticas educativas em tempos de pandemia: relato de experiência

O vídeo, como material didático, oferece grandes possibilidades pedagógicas. Nesse sentido, foram elaborados vários vídeos para complementar a mediação e interação entre familiar mediador, estudante e professor. $O$ professor explica cada atividade a ser realizada e apresenta as perguntas e inferências que devem ser feitas para auxiliar o estudante a se apropriar do conteúdo.

Os vídeos, com roteiros de até quinze minutos, foram produzidos pelas equipes técnicas da Secretaria Municipal de Educação (SME), gravados por professores da Rede Municipal e disponibilizados, quinzenalmente, na rede social Facebook ${ }^{\circledR}$, na mídia social Youtube ${ }^{\circledR}$ da Mantenedora e em grupos fechados de WhatsApp das Unidades Educacionais, administrados pelos gestores.

A proposta de gravação de vídeos foi encaminhada por meio de um convite por e-mail aos professores de todas as Unidades Educacionais, e apenas 37 deles se disponibilizaram a gravar. Esse fato desvela um comportamento receoso do professor, no que se refere ao uso das tecnologias como um recurso potencialmente significante. Fatores como o medo da exposição, o desafio do novo, a necessidade de aprendizagem aligeirada de diferentes ferramentas são anseios que permeiam as práticas educativas, quando deveriam partir do pressuposto de que "[...] a inovação, o olhar crítico, as teorias devem estar vinculadas aos condicionantes e às condições reais de exercício da profissão e contribuir, assim, para a sua evolução e transformação" (TARDIF, 20I4, p. 289). Um repensar da prática pedagógica que considere o conjunto de competências que um professor deve evidenciar para organizar suas aulas, seja com atividades presenciais, seja com não presenciais.

Os cadernos de atividades foram entregues pelos professores. Para tanto, as famílias foram comunicadas, via WhatsApp e de forma escalonada, e compareceram na Unidade Educacional em datas e horários previamente agendados. Os cadernos foram entregues a 99\% dos estudantes, cujos responsáveis assinaram um Termo de Responsabilidade se comprometendo a devolver o material em data específica, para que os docentes realizassem as correções e intervenções necessárias.

Além dos vídeos explicativos e carta de apresentação que compõem a materialidade do caderno, as famílias foram orientadas pelos gestores das Unidades Educacionais, no ato de retirada, a ajudar seus filhos a ter uma rotina de estudo, de preferência no horário em que o estudante frequentava as aulas na escola, num espaço tranquilo, sem interferência de equipamentos eletrônicos, e que realizasse duas atividades por dia, intercalando um Componente Curricular de cada vez. Nesse sentido, as práticas educativas em tempos de pandemia ocorreram por meio de cadernos de atividades, que são entendidos como a alternativa menos impactante no que se refere à garantia da equidade no acesso à educação. Os vídeos assíncronos aparecem como uma tímida ferramenta de proximidade entre professor e família, mas não de efetiva interação, necessitando da ampliação do uso de recursos digitais e ferramentas síncronas para que esse aspecto melhore. 


\section{Considerações finais}

A pandemia do coronavírus (SARS-CoV-2) trouxe às instituições de ensino uma necessidade emergencial de reorganização no que tange às formas de oferta, em todos os níveis de educação. No cenário brasileiro, as escolas amparadas pelas orientações oficiais dos órgãos públicos puderam realizar alterações no calendário escolar, além de promover outras maneiras de ensinar, utilizando a mediação de tecnologias digitais ou outros recursos mais adequados à realidade de cada sistema educacional. São suficientes? Certamente não, mas cada Rede de Ensino buscou um caminho inicial que permitisse fazer novas inferências ao processo de ensino e aprendizagem e novas práticas pedagógicas, em tempos em que há a necessidade de dar continuidade às práticas educativas, reunindo momentos presenciais e não presenciais e a mediação por meio de recursos digitais.

As práticas educativas adotadas objetivaram a promoção e continuidade do processo de ensino e aprendizagem em meio a uma pandemia, considerando a faixa etária dos estudantes, as realidades econômicas das famílias, as questões de acesso às tecnologias digitais e à internet. Os vídeos produzidos para a Educação Infantil cumprem o intuito de aproximar família e escola, mais que a promoção da interação síncrona entre professor e estudante.

Compreendemos a necessidade de ampliar as práticas educativas por meio de tecnologias digitais e da internet, para mediação do processo de ensino e aprendizagem dos estudantes, pois elas têm grande relevância nesse cenário de reorganização escolar, permitindo que a comunicação e diálogo necessários sejam realizados. Contudo, ainda indagamos como as práticas educativas empregadas podem ser ampliadas e extrapolar os vídeos instrucionais? Como fazer desse processo um momento de continuidade de mediação e interação? Percebemos que a adoção dos Cadernos Pedagógicos caracteriza uma possibilidade conveniente, no desafio de manter e dar continuidade aos objetos de conhecimento apresentados no currículo, ainda de que forma adaptada, ao processo de ensino e aprendizagem, sob os pressupostos de que qualquer forma de acesso à educação é melhor que nenhuma forma de acesso à educação. No entanto, há a necessidade de ampliação das práticas de intervenção e interação que promovam o processo de ensino e aprendizagem.

\section{Referências}

BRASIL. Lei $\mathbf{n}^{\circ}$ 13.979, de 6 de fevereiro de 2020a. Dispõe sobre as medidas para enfrentamento da emergência de saúde pública de importância internacional decorrente do coronavírus responsável pelo surto de 2019. Disponível em: <http://www.planalto.gov.br/ccivil_03/_ato20192022/2020/lei/LI 3979.htm>. Acesso em: 30 de mai. de 2020.

BRASIL. Ministério da Educação. Parecer CNE/CEB n 5/2020, de 28 de abril de 2020b. Reorganização do Calendário Escolar e da possibilidade de cômputo de atividades não presenciais para fins de cumprimento da carga horária mínima anual, em razão da Pandemia da COVID-19. Disponível 
em: $\quad<$ http://portal.mec.gov.br/index.php?option=com_docman\&view=download\&alias $=\mid 450 \mathrm{II}$ pcp005-20\&category_slug=marco-2020-pdf\&ltemid=30I 92>. Acesso em: I jun. 2020.

CARVALHO, M. J. L. de. Gênero relato de experiência: um olhar sobre as estratégias cognitivas e discursivas em aquisição de linguagem. I50 f. Dissertação (Mestrado em Linguística). Universidade Federal da Paraíba. João Pessoa, 201l. Disponível em: $<$ https://repositorio.ufpb.br/jspui/handle/tede/6363?locale=pt_BR>. Acesso em: I jun. 2020.

MORAN, I. M. Mudando a educação com metodologias ativas, 2015. (Coleção Mídias Contemporâneas: Convergências Midiáticas, Educação e Cidadania - Aproximações Jovens, v. 2).

OLIVEIRA, Z. R. Educação Infantil: fundamentos e métodos. 3. ed. São Paulo: Cortez, 2007. (Coleção Docência em Formação).

PARANÁ. Decreto $n^{\circ} 4.230$, de 16 de março de 2020. Dispõe sobre as medidas para enfrentamento da emergência de saúde pública de importância internacional decorrente do Coronavírus - COVID-19. Disponível em: <https://leisestaduais.com.br/pr/decreto-n-4230-2020parana-dispoe-sobre-as-medidas-para-enfrentamento-da-emergencia-de-saude-publica-deimportancia-internacional-decorrente-do-coronavirus-covid- 19>. Acesso em: I $^{\circ}$ jun. 2020.

SCHNEUWLY, B. DOLZ, J. (org.). Gêneros orais e escritos na escola. 2. ed. São Paulo: Mercado das Letras, 2010.

TARDIF, M. Saberes docentes e formação profissional. I7. ed. Petrópolis, RJ: Vozes, 2014.

Recebido em: 16 de junho de 2020.

Versão corrigida recebida em: II de agosto de 2020.

Aceito em: 09 de setembro de 2020.

Publicado online em: 26 de março de 202I.

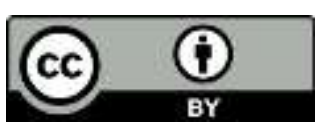

Olhar de professor, Ponta Grossa, v. 24, p. I-8, e-16178.020, 2021.

Disponível em <https://revistas2.uepg.br/index.php/olhardeprofessor> 